\title{
Green and grow
}

\author{
A growing, increasingly affluent and urban human population is driving demand for more food grown in more- \\ sustainable ways. This issue features a suite of articles highlighting how intensification of production on existing \\ farmland and with fewer inputs is an aspirational and data-hungry challenge.
}

t's not easy being green, especially with more and more mouths to feed. Since the Green Revolution of the 1960s, agriculture has been extravagantly successful, feeding more people globally than thought possible but at an unsustainable cost to Earth's ecosystems, biodiversity, water and climate. Since the 1960s, the adoption of high-yield crop varieties and wide use of artificial fertilizers and pesticides increased production markedly, especially in developing regions. As growing populations coalesce into cities, rising incomes and changing tastes are worsening impacts by increasing demand for meat, which requires massive inputs of energy, nutrients and water, and which requires more land. The twin realities of growing and increasingly wealthy populations and worsening environmental impacts have spurred interest in 'sustainable intensification'.

Sustainable intensification (SI) refers to an increase in yields on existing land using fewer harmful inputs and with lesser impacts. Different methods and approaches can contribute, from soil conservation and other traditional management techniques to the high-tech use of drones and data to target fertilizers and pesticides. This issue includes a Focus on Sustainable Intensification, bringing together articles addressing different aspects of this challenge.

In a Perspective, Cassman and Grassini highlight recent trends - spikes in grain prices, plateauing yield increases on existing land, and conversion of wildlands to farms - to motivate considering SI globally. The time frame to act is short given projected population growth, which prioritizes intensifying production in developing 'breadbasket' regions. How can we increase yields while increasing the efficiency of water and nutrient use and reducing soil erosion and greenhouse-gas (GHG) emissions? Beyond genetic improvements, which may take longer, Cassman and Grassini discuss expanding research on production systems in working fields, forming farmer data cooperatives, and monitoring environmental performance at ecologically relevant scales, like watershed ones.

Melding agronomy with information technology is the frontier pursuit of digital agriculture, which uses geospatial

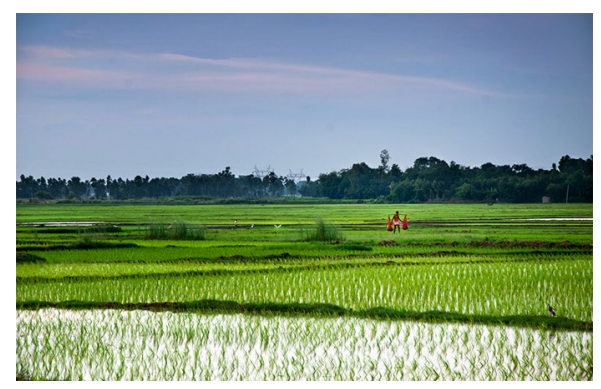

Credit: Partha dalal photography / Moment / Getty

technologies, sensors and algorithms to target what to grow where and how. In a Comment, Basso and Antle agree that genetic improvements are necessary but insufficient, arguing for digital approaches to monitor crops and fields to optimize inputs and planting decisions. Such information can also suggest areas best left as habitat, helping balance agriculture and conservation. That balancing act, they suggest, rather than any singular focus, embraces the spirit of sustainability.

Schramski et al. contend in a second Comment that, while yields, biodiversity, climate, water and nutrients are vital, energy is fundamental. Any honest assessment of agriculture's sustainability must consider it, they argue, and energy use is too often missing in discussions of sustainable intensification of food systems. Mostly fossil-fuel energy powers tractors, drones and computers, and food production requires a large share of the world's growing energy use. Will we track the energy embodied in our increasingly sophisticated inputs, many being touched by long and complex supply chains? As well, increases in efficiency have a notorious tendency to increase resource use, as William Jevons observed long ago for coal.

Intensifying agriculture sustainably, as should now be clear, requires many considerations. For tractability, scholars often focus on one or two aspects or on given regions. A prime motivator for SI is the need to spare land for biodiversity, since agriculture covers a huge and growing share of Earth's land. In an Article, Folberth and colleagues use crop models to show that optimizing crop location and fertilizer inputs could reduce by half the land area needed to produce current food volumes. This only drops modestly by ensuring biodiversity hotspots and important landscapes are spared. And expanded wildlands would store carbon as vegetation regrows, helping combat climate change.

A global focus is important, as most of these papers argue, but regional studies are needed, too. South Asia, anchored by India, is the world's most densely populated region and is relatively vulnerable to climate change. How will it feed itself sustainably? One alternative is conservation agriculture, an ecologically conscious approach prioritizing soil health, diverse cropping systems and wise land management. With a meta-analysis, Jat et al. learn about this approach from South Asian agricultural-experiment stations and farms. Improvements in grain yields, water use and GHG emissions are possible. Some conservation-agriculture techniques, such as zero-tillage farming, have been used for decades or longer. What is old is still new, and this research highlights the importance of focusing on fundamentals.

The authors in this Focus vary in embracing innovation as the answer, but they all value assessment. Intensification requires information, information about what grows best where and when and under what conditions, about what to apply to maximize yields and minimize waste, and about the trade-offs and true costs per calorie. Farmers can only grow more with less if we know more.

For sustainable intensification to achieve its promise, our food-production system must also do more. Even as our tools, models and techniques become ever sophisticated, researchers continue to focus more on yields than on impacts and externalities. Research assessing actual production systems for both and considering impacts fully and forthrightly, from energy use to biocultural diversity loss, is now paramount. Studies on scaling such systems will help move SI from noble aspiration to local, regional and global force. Facing forward, our future is green and knowing.

Published online: 16 April 2020 https://doi.org/10.1038/s41893-020-0525-6 